\title{
Time of day and level of processing
}

\author{
SIMON FOLKARD \\ MRC Perceptual and Cognitive Performance Unit, University of Sussex \\ Falmer, Brighton BNI $9 Q G$, England
}

\begin{abstract}
The time of day at which material is presented has a differential effect on immediate and delayed retention. It has been suggested that this may be mediated by a shift in the type or level of processing that subjects spontaneously engage in. Three experiments are described that were designed to test this suggestion. Experiment 1 found the acoustic similarity effect on short-term memory to be greater at $1000 \mathrm{~h}$ than at $1900 \mathrm{~h}$. Experiment 2 showed the semantic similarity effect on long-term memory to be greater at $1930 \mathrm{~h}$ than at $1030 \mathrm{~h}$. Experiment 3 demonstrated that interposing a short-term memory task between the presentation of a list of words and its subsequent recall had a greater detrimental effect on list learning at $1030 \mathrm{~h}$ than at $1930 \mathrm{~h}$. It is suggested that, if free to do so, subjects may spontaneously place more reliance on maintenance processing in the morning, but more on elaborative processing in the evening.
\end{abstract}

There is considerable evidence that both the immediate and delayed retention of information is affected by the time of day at which it is presented. In the case of immediate retention, presentation in the morning has fairly consistently been found to result in superior performance to presentation later in the day (e.g., Baddeley, Hatter, Scott, \& Snashall, 1970; Blake, 1967; Folkard \& Monk, 1979; Folkard, Monk, Bradbury, \& Rosenthall, 1977; Gates, 1916a, 1916b; Hockey, Davies, \& Gray, 1972; Laird, 1925). In contrast, the available evidence indicates that delayed retention is superior following presentation in the afternoon or evening (Baddeley et al., 1970; Hockey et al., 1972; Folkard \& Monk, in press; Folkard et al., 1977; Monk \& Folkard, 1978). Both these effects have been attributed to an increase in basal arousal level over the day (Colquhoun, 1971), since there is some independent evidence that high arousal has differential effects on immediate and delayed retention. Following the two seminal papers in this area by Kleinsmith and Kaplan (1963) and Walker and Tarte (1963), a large number of studies have investigated this interaction, and these have been reviewed by Craik and Blankstein (1975) and Eysenck (1977). However, it remains unclear as to how the differential effect of arousal on immediate and delayed retention is mediated.

It has been suggested (Folkard \& Monk, in press) that there is a shift in the type or level of processing that subjects adopt over the day. More specifically, it was suggested that subjects may place relatively more reliance on maintenance processing in the morning, but more on semantic processing in the afternoon and

I am extremely grateful to Alan Baddeley for suggesting Experiments 1 and 2, and to Peter Colquhoun for his comments on an earlier draft of this paper. Requests for reprints should be addressed to Simon Folkard, MRC Perceptual and Cognitive Performance Unit, University of Sussex, Falmer, Brighton BN1 9QG, England. evening. This suggestion was based on the findings (1) that a 20-min delay had a far greater detrimental effect on the free recall of prerecency words in the morning than in the afternoon, and (2) that articulatory suppression eliminated the normal morning superiority in the immediate free recall of words by reducing performance at $1000 \mathrm{~h}$ while having no significant effect at $1600 \mathrm{~h}$.

The present studies were designed to obtain rather more direct evidence that the bias toward particular processing strategies that subjects spontaneously engage in varies with time of day, by comparing the magnitude of the "acoustic similarity" and "semantic similarity" effects (Baddeley, 1966a, 1966b) in the morning and evening. If in the morning subjects use more maintenance processing based on the physical characteristics of the item, then the acoustic similarity effect should be greater in the morning. In contrast, if the use of elaborative processing, based on the meaning of the items, increases over the day, then the semantic similarity effect should be greater in the evening.

\section{EXPERIMENT 1: ACOUSTIC SIMILARITY}

This experiment was essentially a replication of that of Baddeley (1966b, Experiment 1, Condition A) that showed acoustic similarity to have a large detrimental effect on the short-term retention of word lists. Independent groups of subjects were tested at 1000 and $1900 \mathrm{~h}$, and the rate of presentation of the word lists was varied for different subgroups of subjects tested at each of these times. These particular times were chosen since detailed examination of the results of the time-ofday studies cited above suggest that they correspond fairly well to the best $(1000 \mathrm{~h})$ and worst $(1900 \mathrm{~h})$ times of day for the immediate memory of syntactically unstructured lists of words or digits. Rate of presentation was manipulated since it was felt that slower 
rates of presentation might result in more semantic processing, and that this factor might thus interact with time of day.

\section{Method}

Subjects. A group of 128 female and 28 male members of the subject panel of the MRC Perceptual and Cognitive Performance Unit, University of Sussex, recruited from the general public by means of advertisements placed in the local press, took part in this experiment. They had an age range of 22-62 years (mean $=39$ years) and were arbitrarily assigned to six groups of 26 subjects that were approximately matched with respect to both age and the proportion of males and females. They were paid at a rate of 70 pence/hour.

Design and Procedure. Three of the groups were tested at $1000 \mathrm{~h}$ and three at $1900 \mathrm{~h}$. At each time, one group was allocated to each of the three different rates of presentation used; these were 2 words $/ \mathrm{sec}, 1$ word $/ \mathrm{sec}$, and 1 word $/ 2 \mathrm{sec}$. The 12 control and 12 acoustically similar lists of words used were the same for all conditions. Each list consisted of five words drawn at random from either the control set (cow, day, bar, few, hot, pen, sup, pit) or the acoustically similar set (mad, man, mat, map, cad, can, cat, cap) of eight words. The lists were presented in the same random order for all conditions and were tape-recorded in a clear voice.

The subjects were tested in subgroups varying in size from 10 to 16 , with two such subgroups forming each experimental group. After each list the subjects were given $15 \mathrm{sec}$ in which to make a correctly ordered written recall. Following Baddeley (1966b), the eight words comprising each set were displayed at the front of the room during both presentation and recall. In addition, a "listening" test was given both at the beginning and end of the experimental session in which the 16 words were read at a rate of 1 word $/ 5 \mathrm{sec}$, and the subjects were required to write down each word as they heard it. Subjects failing either of these tests were replaced.

\section{Results and Discussion}

Following Baddeley (1966b), the results were scored simply in terms of the number of control and acoustically similar lists correctly recalled. The. mean number of lists correctly recalled under the various conditions is given in Table 1 . Of the 156 subjects taking part, 154 showed superior recall of the control lists, indicating that there was a highly reliable acoustic similarity effect. In order to assess the effects of time of day and rate of presentation on the magnitude of this effect, each subject's score on the acoustically confusable lists was expressed as a percentage of his score on the control lists. It should be noted that higher scores thus reflect a reduced acoustic similarity effect. These results are shown in Figure 1, from which it can

Table 1

Mean Number of Acoustically Similar and Control Lists Correctly Recalled (Out of 12) at $1000 \mathrm{~h}$ and $1900 \mathrm{~h}$ at the Different Rates of Presentation

\begin{tabular}{lllll}
\hline \multirow{2}{*}{$\begin{array}{c}\text { Time } \\
\text { of Day }\end{array}$} & Type of List & \multicolumn{3}{c}{ Seconds per Item } \\
\cline { 3 - 5 } $1000 \mathrm{~h}$ & \multicolumn{1}{c}{ Ty } & 1.0 & 2.0 \\
\hline \multirow{3}{*}{$1900 \mathrm{~h}$} & Acoustically Similar & 1.23 & 1.38 & 2.42 \\
& Control & 9.58 & 8.77 & 8.73 \\
& Acoustically Similar & 1.65 & 1.69 & 3.38 \\
& Control & 10.11 & 8.08 & 9.23 \\
\hline
\end{tabular}

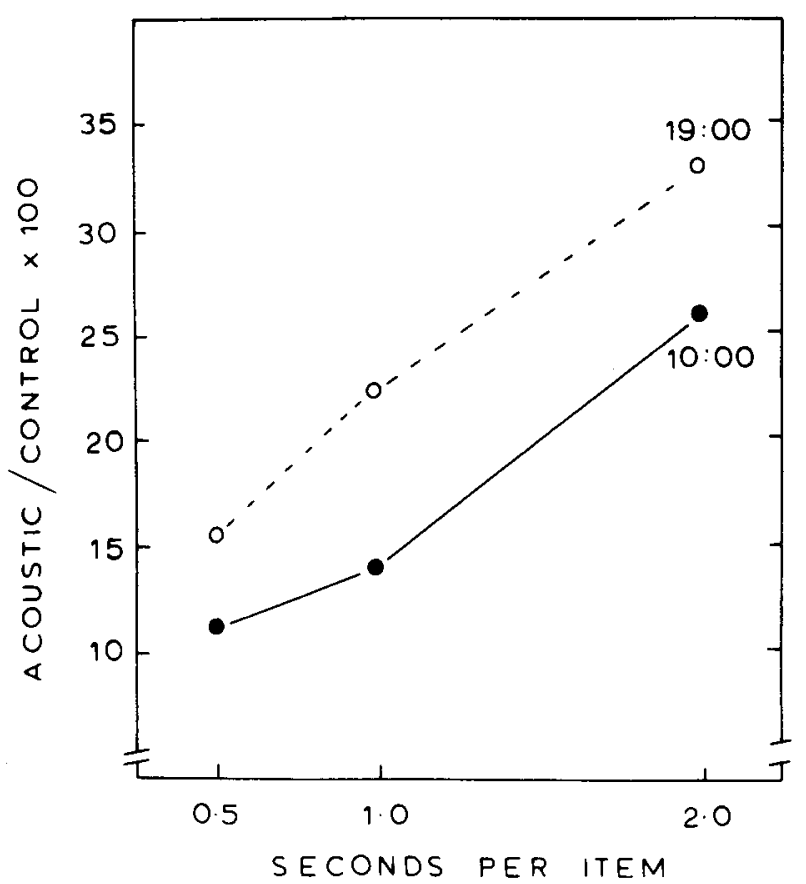

Figure 1. The magnitude of the acoustic similarity effect at $1000 \mathrm{~h}$ and $1900 \mathrm{~h}$ for three different rates of presentation. Note that higher scores reflect a reduced acoustic similarity effect.

be seen that the acoustic similarity effect was greater at $1000 \mathrm{~h}$ than at $1900 \mathrm{~h}$ and reduced with the slowing down of presentation rate at both times.

An analysis of variance based on these scores confirmed that there were significant main effects of both time of day $[F(1,150)=4.23, p<.05]$ and rate of presentation $[\mathrm{F}(2,150)=8.62, \mathrm{p}<.01]$, but no evidence of an interaction between these two factors $(\mathrm{F}<1)$.

These results are clearly consistent with the suggestion that subjects may place more reliance on maintenance processing based on the physical attributes of the items in the morning than in the evening. They also indicate that at the slower rates of presentation, subjects are less affected by acoustic similarity, presumably due to their being able to use more elaborative processing strategies. Indeed, it would be possible to argue that the effect of time of day reflected greater use of semantic processing in the evening, rather than more reliance being placed on maintenance processing in the morning. This point is considered in Experiment 3.

\section{EXPERIMENT 2: SEMANTIC SIMILARITY}

This experiment was a strict replication of that of Baddeley (1966a, Experiment 3, Conditions C and D), in which semantic similarity was found to have a detrimental effect on list learning when the contribution from short-term storage was minimized. Independent groups of subjects received a list of 10 semantically similar adjectives or 10 control adjectives to learn 
at $1030 \mathrm{~h}$ or at $1930 \mathrm{~h}$ and performed a short-term memory task between each presentation of the list and the subsequent recall.

\section{Method}

Subjects. A group of 128 of the subjects who took part in Experiment 1 also took part in this experiment. They were given a 5-min break between the two experiments. They were allocated to four experimental groups of 32 subjects each that were approximately matched with respect to age and the proportion of males and females.

Design and Procedure. Two of the groups were tested at $1030 \mathrm{~h}$ and the remaining two were tested at $1930 \mathrm{~h}$. At each time of day, one group learned the semantically similar list (great, large, big, huge, broad, long, tall, fat, wide, high) and the other learned the control list (good, huge, hot, safe, thin, deep, strong, foul, old, late). The words were presented by a slide projector with an automatic timer. Each word was shown for $3 \mathrm{sec}$, and the slide changeover time was approximately $1.5 \mathrm{sec}$. The lists were shown four times in all, with the order of the words in the list being constant over the four presentations. The subjects' task was to learn this order. Immediately after each presentation, subjects performed a secondary task involving memory for six auditorily presented sequences of nine random digits. Different subjects received different written instructions as to how to encode and/or recall the digits, in order to examine the interaction between type of instruction and time of day. This aspect of the results will be reported elsewhere (Folkard, in press). However, the different types of instructions were balanced over the four experimental groups. The digits were played over loudspeakers at a rate of $1 \mathrm{digit} / \mathrm{sec}$, and the subjects were allowed $15 \mathrm{sec}$ to write down each sequence. After each set of six sequences of digits, the subjects were given 1 min to write down the list of words in its correct order in a column of 10 boxes; this was followed by the next presentation of the word list. During the recalls of the word list, its members were shown at the front of the room in a different order from that on the slides. The subjects were tested in subgroups of between 10 and 16 with two or three subgroups forming each experimental group.

\section{Results and Discussion}

The results were scored in terms of the number of words written in the correct location for each successive recall. The results, expressed as percentages, are shown in Figure 2. Inspection of this figure indicates that there was little evidence of any semantic similarity effect at $1030 \mathrm{~h}$, but a fairly substantial one at $1930 \mathrm{~h}$. As was the case in Baddeley's (1966b) experiment, the effect of semantic similarity was greatest on Trial 4. An analysis of variance based on the Trial 4 scores indicated that there was a significant main effect of semantic similarity $[F(1,124)=8.51, p<.01]$ and a significant interaction between semantic similarity and time of day $[F(1,124)=3.94, p<.05]$. Planned comparisons indicated that there was no reliable semantic similarity effect at $1030 \mathrm{~h}(\mathrm{~F}<1)$, but a highly reliable one at $1930 \mathrm{~h}[\mathrm{~F}(1,124)=12.01, \mathrm{p}<.001]$. Examination of Figure 2 reveals that the greater semantic similarity effect at $1930 \mathrm{~h}$ was due in part to worse performance on the semantically similar list, but it also reflected somewhat better performance on the control list than at $1030 \mathrm{~h}$. Neither of these differences was significant, however.

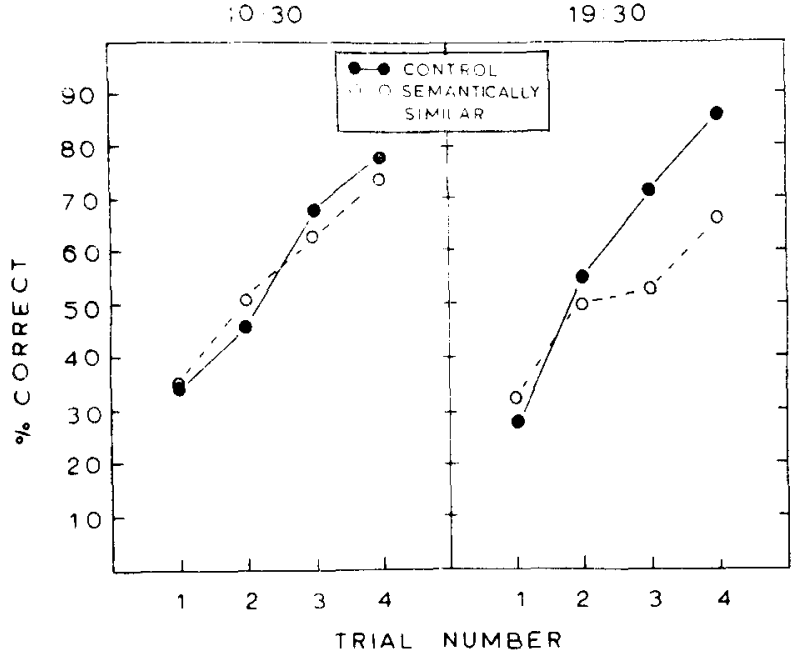

Figure 2. The percent of words correctly recalled from the semantically similar and control lists at $1030 \mathrm{~h}$ and $1930 \mathrm{~h}$ on each trial.

These results thus suggest that subjects do indeed engage in more semantic processing in the evening, and that this has a slightly beneficial effect on performance on the control lists, while interfering with that on the semantically similar list. Indeed, the virtual absence of a semantic similarity effect at $1030 \mathrm{~h}$ suggests that subjects placed little reliance on semantic processing at that time. The slight superiority of performance on the control list at $1930 \mathrm{~h}$ to that at $1030 \mathrm{~h}$ is somewhat surprising in view of the fact that paired associate learning has been noted to be slower in the evening (Lovatt \& Warr, 1968). The most obvious explanation of this apparent discrepancy is that the interposed digit sequence task had a greater detrimental effect on the control list learning at $1030 \mathrm{~h}$ than at $1930 \mathrm{~h}$. Such an explanation would be consistent with the view that subjects place more reliance on maintenance processing in the morning. Thus it seems probable that the performance of the digit sequence task between presentation and recall of the control list had a greater disruptive influence on maintenance processing than on elaborative processing based on the meaning of the words. Experiment 3 was designed to test the suggestion that the performance of a digit sequence task interposed between the presentation of a syntactically unstructured word list and its subsequent recall has a greater disruptive effect in the morning than in the evening.

\section{EXPERIMENT 3}

\section{Method}

Subjects. A group of 74 female and 22 male subjects from the same subject panel as those who participated in the first two experiments took part in Experiment 3. They had an age range of 23-66 years (mean $=41$ years) and were allocated to four experimental groups of 24 subjects each that were approximately matched with respect to age and the proportion of males and females. When tested, some of the subjects had 
just completed Experiment 1, but none of the subjects had taken part in Experiment 2.

Design and Procedure. Two of the experimental groups were tested at $1030 \mathrm{~h}$ and two at $1930 \mathrm{~h}$. All four groups learned the same list of 16 high-frequency monosyllabic concrete nouns. The list was presented in the same manner as in Experiment 2. At each time of day, one of the groups performed the digit sequence task between each presentation of the word list and its subsequent recall (as in Experiment 2) and are thus subsequently referred to as the control groups. The other two groups, referred to as experimental, made their recall immediately after the presentation of the word list and performed the digit sequence task between each recall and the subsequent presentation of the word list. Thus both the control and the experimental groups performed the same digit sequence task between successive recalls of the list, the difference between the groups being simply in terms of the precise point at which they performed the digit sequence task, and hence, in the delay between the presentation and subsequent recall of the word list. In all other respects the design and procedure were the same as in Experiment 2, with the subjects run in subgroups varying in size from 8 to 16 ; two such subgroups comprised each of the four main groups.

\section{Results and Discussion}

The results were scored in the same manner as in Experiment 2 and are shown in Figure 3. Clearly, interposing the digit sequence task between each presentation and its subsequent recall had a far greater effect at $1030 \mathrm{~h}$ than at $1930 \mathrm{~h}$. An analysis of variance indicated that there were significant main effects of condition $[F(1,92)=9.35, p<.01]$ and of trial $[F(3,276)=109.22, p<.001]$ and a significant interaction between time of day and condition $[F(1,92)=5.54$, $p<.05]$. No other main or interaction effects achieved significance ( $p>.25$ in all cases). Separate analyses performed for each time of day indicated that there was a highly significant effect of condition at $1030 \mathrm{~h}$ $[F(1,46)=15.05, p<.001]$, but not at $1930 \mathrm{~h}$ $[F(1,46)<1]$, and that at neither time of day was there

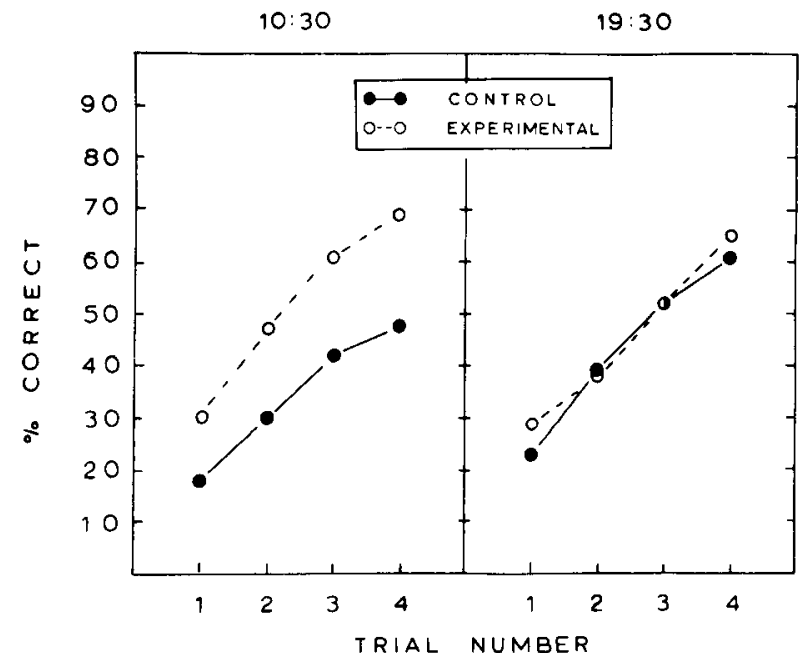

Figure 3. The percent of words correctly recalled under the control (digits interposed between presentation $n_{n}$ and recall ${ }_{\mathfrak{n}}$ ) and experimental (digits interposed between recall $\mathrm{n}_{\mathrm{n}}$ and presentation $_{n+1}$ ) conditions at $1030 \mathrm{~h}$ and $1930 \mathrm{~h}$ on each trial. any evidence of a Condition by Trial interaction $[F(3,138)<1$ in both cases]. Thus the impaired performance in the control condition at $1030 \mathrm{~h}$ would appear to have been relatively constant over the four trials. Inspection of Figure 3 reveals that performance under the control condition was better at $1930 \mathrm{~h}$ than at $1030 \mathrm{~h}$, as was the case in Experiment 2. A planned comparison indicated that this difference was significant $(\mathrm{p}<.05)$. However, as predicted, the $1930 \mathrm{~h}$ superiority was reversed to a slight, and nonsignificant $(\mathrm{p}>.10)$, $1030 \mathrm{~h}$ superiority in the experimental condition.

The results of this experiment thus demonstrate that the performance of the digit sequence task between the presentation of a list of words and its subsequent recall has a greater detrimental effect on performance at $1030 \mathrm{~h}$ than at $1930 \mathrm{~h}$. Thus the discrepancy between the results from the control condition of Experiment 2 and the fact that paired associate learning has been noted to be slower in the evening would appear to be due to the interposed digit sequence task. It is interesting to note that at $1030 \mathrm{~h}$, the slope of the control and experimental learning curves was the same (i.e., there was no interaction between condition and trial), despite the superiority of performance under the experimental condition. It seems probable, therefore, that this superiority did not reflect a difference in learning rate, but the ability to maintain about three items in, for example, an "articulatory loop" or "rehearsal buffer" between presentation and recall on each trial. In view of this, it seems probable that the faster learning of paired associate lists in the morning, as measured by trials to criterion, may reflect increased maintenance of some of the items in a form that benefits immediate but not delayed retention, rather than faster learning per se.

\section{CONCLUSIONS}

The results of these experiments clearly support the suggestion of Folkard and Monk (in press) that subjects engage in more maintenance processing based on the physical characteristics of the items in the morning, but more elaborative processing based on the items' meanings in the evening. However, it is unclear as to whether such a shift in the type of processing subjects engage in should be attributed simply to an increase in basal arousal level over the day (Colquhoun, 1971). While this unidimensional arousal theory has successfully predicted interactions between time of day and other arousal manipulations in the performance of nonmemory tasks (e.g., Blake, 1971; Mullin \& Corcoran, 1977), the available evidence regarding the effects of time of day on memory would appear to necessitate a more complex multifactor theory.

Although the unidimensional arousal theory has successfully predicted an interaction between time of presentation and the delay of recall (Baddeley et al., 
1970; Folkard et al., 1977; Hockey et al., 1972), it has difficulties in accounting for the finding that, in terms of the effects of time of presentation, immediate nemory adjusts to a shift in the sleep-wake cycle more quickly than delayed retention (Folkard \& Monk, 1978). It would thus appear that the factor(s) responsible for ime-of-day effects in immediate memory adjusts paricularly rapidly to such shifts. Indeed, the performance Jf tasks involving "working memory" also adjusts more quickly than that of tasks that place little, if any, eliance on the short-term storage of information Hughes \& Folkard, 1976; Monk, Knauth, Folkard, \& Rutenfranz, 1978).

The interpretation of time-of-day effects on immediate nemory in terms of a unidimensional arousal theory is urther complicated by two other findings in the iterature. First, studies that have examined other factors hought to affect arousal level, such as personality or oud noise, have found high arousal to result in less eliance being placed on semantic processing. These indings have been reviewed by Eysenck (1977). Second, he correlations between extraversion and the immediate nemory for digit sequences at different times of day how the reverse pattern to that which would be redicted by a unidimensional arousal theory (Blake, 1971; Eysenck \& Folkard, in press).

The most promising explanation of these various indings would appear to be that at least two qualiatively different dimensions of arousal underlie the :ffects of time of day on memory, and that high levels on one or more of these dimensions biases attention to he more dominant sources of information (Broadbent, 1971). The problems with this explanation are that, o date, it has proved difficult to identify either the lifferent dimensions of arousal or the factors that letermine dominance. Clearly, further research is needed efore these issues can be resolved.

An alternative interpretation of time-of-day effects in erformance is that they reflect a shift in the degree If cerebral dominance over the day, such that the lominant left hemisphere becomes rather less so in the vening. While admittedly speculative, such an interpreation is consistent with much of the time-of-day iterature and is perhaps rather more testable than an ccount in terms of a multifactor arousal theory and the lominance of different sources of information. A essening in left-hemisphere dominance could account or the improvement over the day typically found in he performance of many perceptual-motor tasks Colquhoun, 1971), and for the decrease in the shorterm memory of verbal items. It might also provide an xplanation of the rather different trends found over the lay for the performance of verbal and visuospatial easoning tasks (Folkard \& Monk, Note 1). In addition, it might be able to account for the interaction found between time of day and various stressors (e.g., Mullin \& Corcoran, 1977), in view of the phylogenetically old "fight or flight" response to stress. It is, however, unclear as to what adaptive function such a circadian (c. $24 \mathrm{~h}$ ) rhythm in cerebral dominance might serve, although it has often been suggested (e.g., Broughton, 1975) that an ultradian (c. $90 \mathrm{~min}$ ) rhythm exists in such dominance.

With regard to the present results, Martin (1978) has shown memory for physically encoded words to be superior when they are presented to the left hemisphere. In contrast, no hemispheric difference was observed for semantically encoded words. Thus a decrease in left-hemisphere dominance over the day might account for the reduced acoustic similarity effect at $1900 \mathrm{~h}$ found in Experiment 1, and for the increased reliance placed on maintenance processing in the morning found in Experiment 3. In view of Martin's (1978) finding of no hemispheric differences for semantically encoded words, the greater semantic similarity effect in the evening found in Experiment 2 is slightly more difficult to account for. There would appear to be two alternative interpretations of this finding. First, it could reflect increased maintenance processing in the morning, rather than an increase in semantic processing in the evening. Such an interpretation would, however, have difficulty in accounting for the results of Experiment 3. Second, if it is assumed that there is some limit to processing capacity, a reduction in maintenance processing in the evening would allow greater semantic processing to take place. If this were the case, increased semantic processing in the evening could be viewed as secondary to, or compensatory for, reduced maintenance processing.

Finally, it should be emphasized that it is unlikely that the shift in the type of processing subjects engage in at different times of day is due to an inability to use any given strategy at a particular time of day. Indeed, there is some evidence that if instructed to do so, subjects can use a maintenance strategy in the evening, and that the time-of-day effect in the immediate memory for digit sequences can be abolished by such instructions (Folkard, in press). The results reported in this paper would thus appear to reflect a change in the bias toward the type of processing strategy that subjects spontaneously adopt at different times of day, rather than a more fundamental change in the ability to use different strategies. Nevertheless, such a change in bias would appear to have important implications for both practical situations where people attempt to commit information to memory, and experimental situations where general conclusions are of ten drawn from studies that have failed to control for potential time-of-day effects. 


\section{REFERENCE NOTE}

1. Folkard, S., \& Monk, T. H. Time of day effects in cognitive performance. Paper presented at the XXIst International Congress of Psychology, Paris, July 1976.

\section{REFERENCES}

Baddeley, A. D. The influence of acoustic and semantic similarity on long-term memory for word sequences. Quarterly Journal of Experimental Psychology, 1966, 18, 302-309. (a)

BADDELEY, A. D. Short-term memory for word sequences as a function of acoustic, semantic and formal similarity. Quarterly Journal of Experimental Psychology, 1966, 18, 362-365. (b)

Baddeley, A. D., Hatter, J. E., Scott, D., \& Snashall, A. Memory and time of day. Quarterly Journal of Experimental Psychology, 1970, 22, 605-609.

Blake, M. J. F. Time of day effects on performance in a range of tasks. Psychonomic Science, 1967, 9, 349-350.

Blake, M. J. F. Temperament and time of day. In W. P. Colquhoun (Ed.), Biological rhythms and human performance. London: Academic Press, 1971.

Broadbent, D. E. Decision and stress. London: Academic Press, 1971.

Broughton, R. Biorhythmic variations in consciousness and psychological functions. Canadian Psychological Review, 1975, 16, 217-239.

Colquhoun, W. P. Circadian variations in mental efficiency. In W. P. Colquhoun (Ed.), Biological rhythms and human performance. London: Academic Press, 1971.

Craik, F. I. M., \& Blankenstein, K. R. Psychophysiology and human memory. In P. H. Venables \& M. J. Christie (Eds.), Research in psychophysiology. London: Wiley, 1975.

Eysenck, M. W. Human memory: Theory, research and individual differences. Oxford: Pergamon Press, 1977.

Eysenck, M. W., \& Folkard, S. Personality, time of day, and caffeine: Some theoretical and conceptual problems in Revelle et al. Journal of Experimental Psychology: General, in press.

Folkard, S. Changes in immediate memory strategy under induced muscle tension and with time of day. Quarterly Journal of Experimental Psychology, in press.

Folkard, S., \& Monk, T. H. Time of day effects in immediate and delayed memory. In M. M. Gruneberg, P. E. Morris, \& R. N. Sykes (Eds.), Practical aspects of memory. London: Academic Press, 1978.
Folkard, S., \& Monk, T. H. Time of day and processing strategy in free recall. Quarterly Journal of Experimental Psychology, in press.

Folkard, S., Monk, T. H., Bradeury, R., \& Rosenthall, J. Time of day effects in school children's immediate and delayed recall of meaningful material. British Journal of Psychology, $1977,68,45-50$.

Gates, A. I. Diurnal variations in memory and association. University of California Publications in Psychology, 1916, 1, 323-344. (a)

Gates, A. I. Variations in efficiency during the day, together with practice effects, sex differences, and correlations. University of California Publications in Psychology, 1916, 1, 1-156. (b)

Hockey, G. R. J., Davies, S., \& Gray, M. M. Forgetting as a function of sleep at different times of day. Quarterly Journal of Experimental Psychology, 1972, 24, 386-393.

Hughes, D. G., \& Folkard, S. Adaptation to an 8-h shift in living routine by members of a socially isolated community. Nature, 1976, 264, 232-234.

Kle insmith, L. J., \& Kaplan, S. Paired-associate learning as a function of arousal and interpolated interval. Journal of Experimental Psychology, 1963, 65, 190-193.

LAIRD, D. A. Relative performance of college students as conditioned by time of day and day of week. Journal of Experimental Psychology, 1925, 8, 50-63.

LovatT, D. J., \& W ARR, P. B. Recall after sleep. American Journal of Psychology, 1968, 81, 253-257.

MARTIN, M. Hemispheric asymmetries for physical and semantic selection of visually presented words. Neuropsychologia, 1978, 16, 717-724.

Monk, T. H., \& Folkard, S. Concealed inefficiency of late night study. Nature, 1978, 273, 296-297.

Monk, T. H., Knauth, P., Folkard, S., \& Rutenfranz, J. Memory based performance measures in studies of shiftwork. Ergonomics, 1978, 21, 819-826.

Mullin, J., \& Corcoran, D. W. J. Interaction of task amplitude with circadian variation in auditory vigilance performance. Ergonomics, 1977, 20, 193-200.

W ALKER, E. L., \& TARTE, R. D. Memory storage as a function of time with homogeneous and heterogeneous lists. Journal of Verbal Learning and Verbal Behavior, 1963, 2, 113-119.

(Received for publication January 26, 1979; revision accepted May 8, 1979.) 